\title{
ROLES OF HOMOARGININE IN THE CARDIOVASCULAR SYSTEM
}

\author{
EKUA, N. E. - CHE, D. * - ADAMS, S. - QIN, G. - ZHAO, B. - JIANG, H. \\ College of Animal Science and Technology, Jilin Agricultural University \\ Changchun 130118, China
}

Jilin Provincial Key Lab of Animal Nutrition and Feed Science, Jilin Agricultural University
Changchun 130118, China

Key Lab of Animal Production, Product Quality and Security, Ministry of Education, Jilin Agricultural University, Changchun 130118, China

*Corresponding author

e-mail: chedongsheng@163.com; phone: +86-136-4431-9554

(Received $5^{\text {th }}$ Mar 2019; accepted $13^{\text {th }}$ Jun 2019)

\begin{abstract}
Homoarginine is a non-protein amino acid which is structurally similar to arginine. Research shows that homoarginine is produced in a small quantity in the body of humans and animals and it is suggested to be found in some organs such as the kidney, liver, brain and body fluids; blood and urine. Homoarginine is synthesized from arginine and lysine by the catalytic action of arginine: glycine amidinotransferase (AGAT) which is also responsible for the synthesis of guanidinoacetate, the precursor of creatine. High concentration of homoarginine has been reported to inhibit arginase which is a substrate in the synthesis of nitric oxide. Recent reports have also indicated that low homoarginine concentrations are a risk marker for cardiovascular diseases and death. More research needs to be done to improve knowledge on the physiological role of homoarginine and its application in clinical studies and pharmacy with the aim of coming up with possible medication and ways to combat cardiovascular diseases. This review seeks to summarize the role of homoarginine in the cardiovascular system.
\end{abstract}

Keywords: arginine: glycine amidinotransferase, disease, nitric oxide, smooth muscle cells, synthesis

\section{Introduction}

As a cationic amino acid, homoarginine has structural similarities to arginine (Fig. 1 ) and formed from lysine (Papageorgiou et al., 2015). Its synthesis occurs in the kidney and the liver (Ryan and Wells, 1964). The enzyme that is responsible for homoarginine synthesis remains unknown (Tsikas and Kayacelebi, 2014) however, it is assumed to be arginine: glycine amidinotransferase (AGAT) which may help in the synthesis of homoarginine from lysine and arginine in animals (Hou et al., 2015; Tsikas and $\mathrm{Wu}$, 2015). According to research, homoarginine inhibits arginase and arginine transportation by cells (Hou et al., 2015). The level of homoarginine concentration in the body has been reported to be higher in children as compared to adults - children have a high level of protein synthesis to support growth (Atzler et al., 2014). Some researchers found that its concentration in the plasma declines with age, which results in cardiovascular, cerebrovascular diseases and death in animals and humans (Atzler et al., 2015; Hou et al., 2015). Studies have shown that homoarginine may impact nitric oxide metabolism, endothelial function, insulin secretion, and inhibit platelet aggregation; these are important for the maintenance of cardiovascular health (Bretscher et al., 2003; Stockebrand et al., 2015). Based on these functions, some scientists have showed that homoarginine is an independent risk biomarker of cardiovascular diseases (Tomaschitz 
et al., 2014; Kayacelebi et al., 2015; Chafai et al., 2017; Seppälä et al., 2017). Current investigations on the usage of homoarginine in both human and animals in relations to different conditions such as disease states, growth promotion, nutrient transport and metabolism, foetal and neonatal growth and survival is increasingly gaining scientific attention. Homoarginine has been associated with different disease states in both human and animals however there are limited investigations involving homoarginine. Therefore, this current review seeks to summarize the role of homoarginine in the cardiovascular systems, including Atherosclerosis, Type 2 diabetes mellitus, and Stroke.

\section{Synthesis of homoarginine}

Arginine and asymmetric dimethylarginine (ADMA) are usually measured at the same time with homoarginine, which is a homolog of arginine (Fig. 1) (Teerlink et al., 2002; Davids et al., 2012b). Homoarginine is solid and it has a melting point of $213-215^{\circ} \mathrm{C}$ with a molecular weight of $188.231 \mathrm{~g} / \mathrm{mol}$. Its formation is endogenous (Seppälä et al., 2017). Some legumes are rich in nonprotein amino acids, including homoarginine; the grass pea (Lathyrus sativus L.), which is rich in homoarginine serves as food for humans and feed for domestic animals (Bell, 2003; Rao, 2011). Research shows that plasma concentration of homoarginine in healthy adults is about $2 \mu \mathrm{M}$ (Hou et al., 2015; May et al., 2015; Hanff et al., 2016). A study on rats recorded 20 min as the half-life of homoarginine (Günes et al., 2017; Adams et al., 2019). It is known to play a role in the arginine/nitric oxide pathway by acting as a substrate (Haghikia et al., 2017). According to research, homoarginine's ability to inhibit either arginase or protein arginine methyltransferase (PRMTs) makes it increase the production of nitric oxide (Michel, 2013; Vogl et al., 2015) and this might have a positive impact on endothelial function (Valtonen et al., 2008). Recent reports have indicated that low homoarginine concentrations is a risk factor for cardiovascular conditions and death in people as well as kidney disease patients (Atzler et al., 2014; Pilz et al., 2014; Tomaschitz et al., 2014; Vogl et al., 2015).The physiological role of homoarginine is still being studied by some researchers.

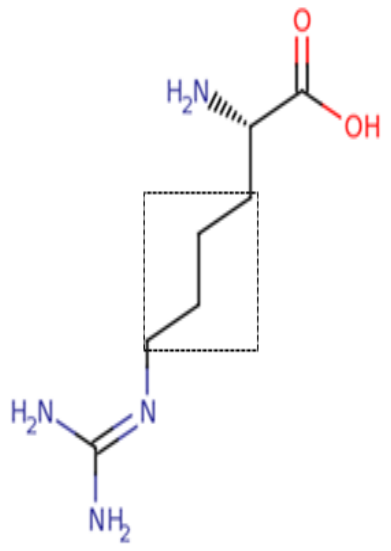

Homoarginine



Arginine

Figure 1. The structural formula of arginine and its homolog homoarginine which differs by a methylene group (-CH2-) 


\section{Homoarginine metabolism in vascular system}

\section{Metabolism of Homoarginine}

Studies over the past fifty years have led to an understanding of some of the physiological and biochemical roles of homoarginine in humans and animals (Hou et al., 2015). Homoarginine is produced in a small quantity in the body of humans and animals (Hou et al., 2015). It is suggested to be found in some organs such as the kidney, liver, brain and body fluids; blood and urine (Valtonen et al., 2008). A research on the possible pathways for homoarginine showed that a mitochondrial enzyme found in the kidney, which is arginine: glycine amidinotransferase (AGAT), catalyses the transformation of glycine and arginine to guanidinoacetate (GAA) and ornithine, and GAA is methylated to creatine with the help of guanidinoacetate N-methyltransferase (GAMT) for energy metabolism. Homoarginine is produced when AGAT uses lysine instead of glycine (Davids et al., 2012a) (Fig. 2). In the urea cycle, homoarginine is formed when ornithine is replaced by lysine. The ornithine transcarbamoylase (OTC) enzyme is important in this metabolic pathway. This enzyme catalyses the transamidination of lysine which facilitates the production of homoarginine (Davids et al., 2012a). Homoarginine also inhibits arginase and acts as a substrate for NO synthase to form NO, which performs a critical function in vasodilation and is important in the regulation of blood pressure (März et al., 2010).

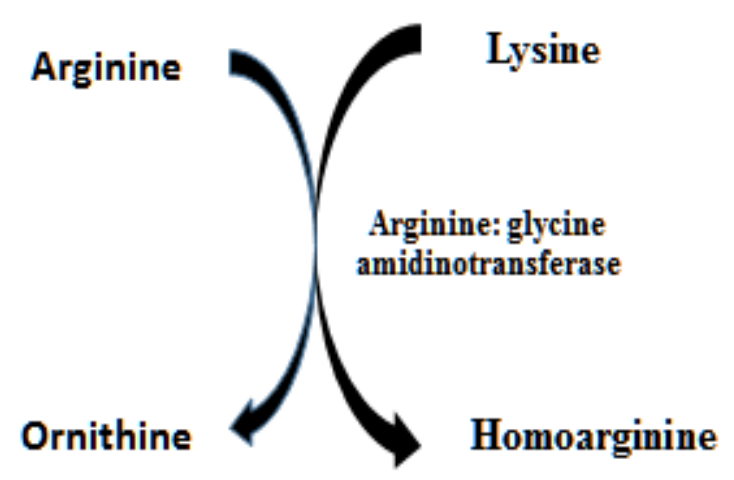

Figure 2. A schematic diagram showing the synthesis of Homoarginine and Ornithine from Arginine and lysine using Arginine: glycine amidinotransferase

\section{Nitric Oxide and Nitric Oxide Synthases}

Nitric oxide (NO) is formed during the complex oxidation reaction from arginine and oxygen $(\mathrm{O} 2)$. NO is produced with the help of enzyme nitric oxide synthase (NOS), with the endothelial cells of blood vessels being its first location. The enzyme is called synthase, not synthetase, because there is no need of adenosine triphosphate (ATP) for its action (Arzumanian et al., 2003). The nitric oxide synthase plays active role in the production of NO. They are neuronal (nNOS), endothelial (eNOS) and inducible (iNOS). Oxygen, nicotinamide-adenine-dinucleotide phosphate (NADPH), tetrahydrobiopterin and flavin adenine nucleotides are known as the co-factors for NOS (Kassim et al., 2010; Tousoulis et al., 2012).

Expression of Neuronal NOS occurs in specific neurons in the brain with $\mathrm{Ca}^{2+}$ and calmodulin regulating the activities of enzymes (Zhou and Zhu, 2009). According to 
immunohistochemistry, nNOS could be located in the spinal cord, the sympathetic ganglia and adrenal glands, in kidney macula densa cells, and in the vascular smooth muscle (Förstermann et al., 1994). nNOS is known to play a role in physiological functions such as memory, learning, and neurogenesis (Zhou and Zhu, 2009). Research has shown that the central regulation of blood pressure in the central nervous system (CNS) is assisted by NO formed by nNOS (Sakuma et al., 1992; El karib et al., 1993). A data on human studies indicated that nNOS perform a significant function in vascular tone regulation (Melikian et al., 2009). When eNOS becomes dysfunctional, low level of nNOS expressed in the vascular smooth muscle cells maintains vasodilation (Schwarz et al., 1999). The endothelial cells are known as the site for endothelial NOS production. Research has also shown that the isozyme is found in cardiac myocytes, platelets, LLC-PK1 kidney tubular epithelial cells and certain neurons of the brain, and in (Förstermann et al., 1994). Numerous essential cardiovascular functions appear to be regulated by eNOS which serves as a homeostatic regulator. Endothelial NOS-derived NO stimulates soluble guanylyl cyclase and increases cyclic guanosine monophosphate (cGMP) in smooth muscle cells thereby dilates all types of blood vessels (Förstermann and Sessa, 2011). Blood pressure rises as a result of deletion of the eNOS gene (Huang et al., 1995; Shesely et al., 1996). The inhibition of platelet aggregation and adhesion to the vascular wall occurs when nitric oxide is released towards the vascular lumen (Alheid et al., 1987). Evidence has also indicated that endothelial NO inhibits leucocyte adhesion and vascular inflammation. An early event in the development of atherosclerosis is leucocyte adherence and therefore, NO may act against the onset of atherogenesis (Förstermann and Sessa, 2011). Expression of inducible NOS can be instigated by bacterial lipopolysaccharide, cytokines, and other agents (Förstermann, 2000). The production of high quantity of NO by inducible NOS occurs when induced in macrophages which indicates a major cytotoxic principle of those cells (Nathan and Hibbs Jr, 1991). Arginine is utilized by all isoforms of NOS as the substrate, with molecular oxygen and decreased NADPH being utilized as co-substrates (Förstermann and Sessa, 2011).

\section{Functions of homoarginine in vascular system}

\section{Nitric oxide synthesis}

Nitric oxide which has been studied extensively due to its health effects in the body is an inorganic molecule that exists in mammalian biology (Ziolo et al., 2001). The formation of nitrogen oxides occurs when NO; an unstable free-radical gas reacts rapidly with oxygen. It is soluble and has a molecular weight of $30.006 \mathrm{~g} / \mathrm{mol}$. Nitric oxide has a half-life of $\sim 6-30 \mathrm{~s}$ (Tousoulis et al., 2012). The nitric oxide synthases catalyse the oxidation of arginine to produce nitric oxide in mammals. eNOS and nNOS are constitutively expressed and are referred to as $\mathrm{Ca}^{2+}$-dependent enzymes (Förstermann and Sessa, 2011). It serves as a main paracrine and autocrine mediator of immune regulation and vascular relaxation in the body (Moncada, 1991). In the endothelium, nitric oxide serves as a central signal transduction pathway (Ignarro et al., 1999). Homoarginine is a weak substrate for nitric oxide synthase (NOS) and can produce NO. When homoarginine hinders the activity of arginase, it may increase arginine and NO production (Hrabak et al., 1994). Nitric oxide aids in blood pressure regulation, inhibition of platelet aggregation, platelet adhesion inhibition, and neurotransmission (Loscalzo and Vita, 2000; Atzler et al., 2015). Arginine performs 
various functions in living organisms (März et al., 2010; Haghikia et al., 2017), but the roles of homoarginine need more research (Seppälä et al., 2017). A study suggested that homoarginine competes with arginine, which causes a decrease in NO synthesis (Alesutan et al., 2016). An intravenous homoarginine infusion research done on rats showed an increase in serum concentration of homoarginine and ornithine (Dellera et al., 2016). According to the results obtained, it was suggested that anti-proliferative effects may be exerted by homoarginine; increasing the release of NO from vascular cells (Durante, 2013; Dellera et al., 2016), and by ornithine; acting as an arginase inhibitor to increase NO availability (Durante, 2013; Dellera et al., 2016). Homoarginine plays an important role in NO synthesis even though its concentration is little in the serum and plasma of humans and animals.

\section{Cardiovascular diseases}

Vascular smooth muscle cells perform a major function in vascular diseases (Qiu et al., 2014). Studies have shown that the abnormal proliferation and migration of vascular smooth cells are the main constituents of hypertension, atherosclerosis and vascular sterosis after vessel transplant (Kockx and Knaapen, 2000; González-Navarro et al., 2010). Homoarginine is a less efficient NOS substrate than arginine, but competes with arginine for NO synthesis by hindering the regular production of NO (März et al., 2010). Research has reported that critical cardiovascular conditions are as a result of both high and low hArg levels whereas increased vascular resistance is as a result of high homoarginine levels. Prospective research indicated that cardiovascular death and stroke were caused by low homoarginine levels (Tomaschitz et al., 2014; Chafai et al., 2017; Seppälä et al., 2017). Endothelium plays a main role in the vasculature by ensuring the promotion and maintenance of a protective environment via endothelial cell-derived vasoactive factors (Guzik et al., 2004; Papageorgiou et al., 2015). Some scientists investigated on how low level of homoarginine is related to dilation and a reduced function of the left ventricle and their findings indicated that high homoarginine is linked to lower left ventricle thickening, higher ejection fraction and lower Nterminal pro B-type natriuretic peptide (NTproBNP) (Bahls et al., 2018).

\section{Atherosclerosis}

Atherosclerosis, a disease of the arterial wall occurs at sensitive areas in the main arteries (Insull Jr, 2009). It starts off by lipid retention, oxidation, and modification, which leads to incurable swelling and causes thrombosis or stenosis (Insull Jr, 2009). Many factors may cause atherosclerosis by their effects on low-density lipoprotein (LDL) particles and inflammation (De Groot et al., 2000; Tomkin and Owens, 2012). These factors often include tobacco smoking, hypertension, obesity, diabetes, and genetic susceptibility (Insull Jr, 2009). Aortic stiffness, the inverse measure of aortic distensibility (AD), is also known as a cardiovascular risk marker aside the common factors for atherosclerosis (Kronzon and Tunick, 2006; Haghikia et al., 2017). Atherosclerosis has been reported as a main cause of death and morbidity across the globe. Studies have shown that homoarginine promotes vascular calcification (Alesutan et al., 2016; Haghikia et al., 2017) and it may be involved in the pathogenesis of atherosclerosis (Seppälä et al., 2017). However, there are inadequate information on the association between low homoarginine concentrations and the occurrence of atherosclerosis. 


\section{Type 2 diabetes mellitus}

Type 2 diabetes mellitus (T2DM) is a metabolic disorder which is distinguished by insulin deficiency, hyperglycemia, and insulin resistance (Olokoba et al., 2012). An interaction between genetic, environmental and behavioural risk factors can also cause this disorder (Chen et al., 2012). Recent evidence has reported that homoarginine concentrations were lower at higher age, lower body mass index (BMI), lower albumin, lower haemoglobin, and were lower in females as compared to males (Drechsler et al., 2011). Low homoarginine concentrations were also associated with a longer history of diabetes mellitus and higher levels of C-reactive protein (Drechsler et al., 2011). Low serum concentration of homoarginine is independently associated with T2DM patients that can lead to death.

\section{Stroke}

Stroke is as a result of the cessation of blood flow to the brain which can cause disability and death. Ischemic stroke is caused by thrombosis due to atherosclerosis. Some common risk factors associated with stroke are hypertension, stress and age. In the LURIC study, low serum homoarginine concentrations were found to be a novel risk factor for fatal strokes (Pilz et al., 2011). A recent report on a homoarginine supplementation in stroke-infected mice indicated a noticeable decrease in homoarginine in the plasma from AGAT null mice, which is related to an increase in the size of stroke (Choe et al., 2013). According to Choe et al. (2013), there was a decrease in the death rate of patients with ischemic stroke which was independently associated with high homoarginine levels recorded. In the Harburg Stroke Study, which involved 137 patients affected with ischemic stroke, it was reported that plasma homoarginine concentrations were significantly decreased in patients who were near death, nonfatal recurrent stroke and nonfatal myocardial infarction compared with those without the condition (Choe et al., 2012).

\section{Conclusion}

It has become evident that homoarginine is a new biomarker for cardiovascular diseases by its involvement in NO production. Low serum concentration of homoarginine has been reported in subjects suffering from cardiovascular, cerebrovascular and renal diseases as compared to healthy subjects. More research needs to be done to understand the physiological role of homoarginine and its application in clinical studies and pharmacy as a possible medication for the cure of associated diseases.

Acknowledgements. The authors would like to appreciate the national key research and development program of China (2017YFD0502104), and the scientific project of Jilin province (20170309003NY) for providing the financial support to publish this review.

Declaration of interests. The authors declare that there is no conflict of interests. 


\section{REFERENCES}

[1] Adams, S., Che, D., Qin, G., Farouk, M. H., Hailong, J., Rui, H. (2019): Novel Biosynthesis, Metabolism and Physiological Functions of L-Homoarginine. - Current Protein and Peptide Science 20(2): 184-193.

[2] Alesutan, I., Feger, M., Tuffaha, R., Castor, T., Musculus, K., Buehling, S. S., Heine, C. L., Kuro-o, M., Pieske, B., Schmidt, K. (2016): Augmentation of phosphate-induced osteo/chondrogenic transformation of vascular smooth muscle cells by homoarginine. Cardiovascular research 110(3): 408-418.

[3] Alheid, U., Frölich, J. C., Förstermann, U. (1987): Endothelium-derived relaxing factor from cultured human endothelial cells inhibits aggregation of human platelets. Thrombosis research 47(5): 561-571.

[4] Arzumanian, V., Stankevicius, E., Laukeviciene, A., Kevelaitis, E. (2003): Mechanisms of nitric oxide synthesis and action in cells. - Medicina (Kaunas) 39(6): 535-541.

[5] Atzler, D., Gore, M. O., Ayers, C. R., Choe, C.-u., Böger, R. H., de Lemos, J. A., McGuire, D. K., Schwedhelm, E. (2014): Homoarginine and cardiovascular outcome in the population-based Dallas Heart Study. - Arteriosclerosis, thrombosis, and vascular biology:ATVBAHA. 114.304398.

[6] Atzler, D., Schwedhelm, E., Choe, C.-u. (2015): L-homoarginine and cardiovascular disease. - Current Opinion in Clinical Nutrition \& Metabolic Care 18(1): 83-88.

[7] Bahls, M., Atzler, D., Markus, M., Friedrich, N., Böger, R., Völzke, H., Felix, S., Schwedhelm, E., Dörr, M. (2018): Low-Circulating Homoarginine is Associated with Dilatation and Decreased Function of the Left Ventricle in the General Population. Biomolecules 8(3):63.

[8] Bell, E. A. (2003): Nonprotein amino acids of plants: significance in medicine, nutrition, and agriculture. - Journal of agricultural and food chemistry 51(10): 2854-2865.

[9] Bretscher, L. E., Li, H., Poulos, T. L., Griffith, O. W. (2003): Structural characterization and kinetics of nitric-oxide synthase inhibition by novel N5-(iminoalkyl)-and N5(iminoalkenyl)-ornithines. - Journal of Biological Chemistry 278(47): 46789-46797.

[10] Chafai, A., Fromm, M. F., König, J., Maas, R. (2017): The prognostic biomarker Lhomoarginine is a substrate of the cationic amino acid transporters CAT1, CAT2A and CAT2B. - Scientific Reports 7(1): 4767.

[11] Chen, L., Magliano, D. J., Zimmet, P. Z. (2012): The worldwide epidemiology of type 2 diabetes mellitus - present and future perspectives. - Nature reviews endocrinology 8(4): 228.

[12] Choe, C.-u., Nabuurs, C., Stockebrand, M. C., Neu, A., Nunes, P., Morellini, F., Sauter, K., Schillemeit, S., Hermans-Borgmeyer, I., Marescau, B. (2012): L-arginine: glycine amidinotransferase deficiency protects from metabolic syndrome. - Human molecular genetics 22(1): 110-123.

[13] Choe, C.-u., Atzler, D., Wild, P. S., Carter, A. M., Böger, R. H., Ojeda, F., Simova, O., Stockebrand, M., Lackner, K., Nabuurs, C. (2013): Homoarginine levels are regulated by Larginine: glycine amidinotransferase and affect stroke outcome: results from human and murine studies. - Circulation: CIRCULATIONAHA. 112.000580.

[14] Davids, M., Ndika, J. D., Salomons, G. S., Blom, H. J., Teerlink, T. (2012a): Promiscuous activity of arginine: glycine amidinotransferase is responsible for the synthesis of the novel cardiovascular risk factor homoarginine. - FEBS letters 586(20): 3653-3657.

[15] Davids, M., Swieringa, E., Palm, F., Smith, D. E., Smulders, Y. M., Scheffer, P. G., Blom, H. J., Teerlink, T. (2012b): Simultaneous determination of asymmetric and symmetric dimethylarginine, L-monomethylarginine, L-arginine, and L-homoarginine in biological samples using stable isotope dilution liquid chromatography tandem mass spectrometry. Journal of Chromatography B 900: 38-47. 
[16] De Groot, L., Chrousos, G., Dungan, K., Feingold, K., Grossman, A., Hershman, J., Koch, C., Korbonits, M., McLachlan, R., New, M. (2000): The Role of Lipids and Lipoproteins in Atherosclerosis--Endotext.

[17] Dellera, F., Ganzetti, G., Froio, A., Manzini, S., Busnelli, M., Meinitzer, A., Sirtori, C., Chiesa, G., Parolini, C. (2016): L-homoarginine administration reduces neointimal hyperplasia in balloon-injured rat carotids. - Thrombosis and haemostasis 116(2): 400-402.

[18] Drechsler, C., Meinitzer, A., Pilz, S., Krane, V., Tomaschitz, A., Ritz, E., März, W., Wanner, C. (2011): Homoarginine, heart failure, and sudden cardiac death in haemodialysis patients. - European journal of heart failure 13(8): 852-859.

[19] Durante, W. (2013): Role of arginase in vessel wall remodeling. - Frontiers in immunology 4: 111.

[20] El karib, A. O., Sheng, J., Betz, A. L., Malvin, R. L. (1993): The central effects of a nitric oxide synthase inhibitor ( $\mathrm{N} \omega$-nitro-L-arginine) on blood pressure and plasma renin. Clinical and experimental hypertension 15(5): 819-832.

[21] Förstermann, U., Closs, E. I., Pollock, J. S., Nakane, M., Schwarz, P., Gath, I., Kleinert, H. (1994): Nitric oxide synthase isozymes. Characterization, purification, molecular cloning, and functions. - Hypertension 23(6 Pt 2): 1121-1131.

[22] Förstermann, U. (2000): Regulation of nitric oxide synthase expression and activity, Nitric Oxide. - Springer. p. 71-91.

[23] Förstermann, U., Sessa, W. C. (2011): Nitric oxide synthases: regulation and function. European heart journal 33(7): 829-837.

[24] González-Navarro, H., Nabah, Y. N. A., Vinué, Á., Andrés-Manzano, M. J., Collado, M., Serrano, M., Andrés, V. (2010): p19ARFDeficiency Reduces Macrophage and Vascular Smooth Muscle Cell Apoptosis and Aggravates Atherosclerosis. - Journal of the American College of Cardiology 55(20): 2258-2268.

[25] Guzik, T. J., Sadowski, J., Kapelak, B., Jopek, A., Rudzinski, P., Pillai, R., Korbut, R., Channon, K. M. (2004): Systemic regulation of vascular NAD (P) H oxidase activity and nox isoform expression in human arteries and veins. - Arteriosclerosis, thrombosis, and vascular biology 24(9): 1614-1620.

[26] Günes, D. N., Kayacelebi, A. A., Hanff, E., Lundgren, J., Redfors, B., Tsikas, D. (2017): Metabolism and distribution of pharmacological homoarginine in plasma and main organs of the anesthetized rat. - Amino acids 49(12): 2033-2044.

[27] Haghikia, A., Yanchev, G. R., Kayacelebi, A. A., Hanff, E., Bledau, N., Widera, C., Sonnenschein, K., Haghikia, A., Weissenborn, K., Bauersachs, J. (2017): The role of Larginine/L-homoarginine/nitric oxide pathway for aortic distensibility and intima-media thickness in stroke patients. - Amino acids 49(6): 1111-1121.

[28] Hanff, E., Kayacelebi, A. A., Yanchev, G. R., Maassen, N., Haghikia, A., Tsikas, D. (2016): Simultaneous stable-isotope dilution GC-MS measurement of homoarginine, guanidinoacetate and their common precursor arginine in plasma and their interrelationships in healthy and diseased humans. - Amino acids 48(3): 721-732. doi: 10.1007/s00726-015-2120-0.

[29] Hou, Y., Jia, S., Nawaratna, G., Hu, S., Dahanayaka, S., Bazer, F. W., Wu, G. (2015): Analysis of 1-homoarginine in biological samples by HPLC involving precolumn derivatization with o-phthalaldehyde and N-acetyl-1-cysteine. - Amino acids 47(9): 20052014.

[30] Hrabak, A., Bajor, T., Temesi, A. (1994): Comparison of Substrate and Inhibitor Specificity of Arginase and Nitric Oxide (NO) Synthase for Arginine Analogs and Related Compounds in Murine and Rat Macrophages. - Biochemical and biophysical research communications 198(1): 206-212.

[31] Huang, P. L., Huang, Z., Mashimo, H., Bloch, K. D., Moskowitz, M. A., Bevan, J. A., Fishman, M. C. (1995): Hypertension in mice lacking the gene for endothelial nitric oxide synthase. - Nature 377(6546): 239. 
[32] Ignarro, L. J., Cirino, G., Casini, A., Napoli, C. (1999): Nitric oxide as a signaling molecule in the vascular system: an overview. - Journal of cardiovascular pharmacology 34(6): 879886.

[33] Insull Jr, W. (2009): The pathology of atherosclerosis: plaque development and plaque responses to medical treatment. - The American journal of medicine 122(1): S3-S14.

[34] Kassim, M., Achoui, M., Mansor, M., Yusoff, K. M. (2010): The inhibitory effects of Gelam honey and its extracts on nitric oxide and prostaglandin E2 in inflammatory tissues. - Fitoterapia 81(8): 1196-1201.

[35] Kayacelebi, A. A., Willers, J., Pham, V. V., Hahn, A., Schneider, J. Y., Rothmann, S., Frölich, J. C., Tsikas, D. (2015): Plasma homoarginine, arginine, asymmetric dimethylarginine and total homocysteine interrelationships in rheumatoid arthritis, coronary artery disease and peripheral artery occlusion disease. - Amino acids 47(9): 1885-1891.

[36] Kockx, M. M., Knaapen, M. W. (2000): The role of apoptosis in vascular disease. - The Journal of pathology 190(3): 267-280.

[37] Kronzon, I., Tunick, P. A. (2006): Aortic atherosclerotic disease and stroke. - Circulation 114(1): 63-75.

[38] Loscalzo, J., Vita, J. A. (2000): Nitric oxide and the cardiovascular system. - Springer Science \& Business Media.

[39] März, W., Meinitzer, A., Drechsler, C., Pilz, S., Krane, V., Kleber, M. E., Fischer, J., Winkelmann, B. R., Böhm, B. O., Ritz, E. (2010): Homoarginine, cardiovascular risk, and mortality. - Circulation 122(10): 967-975.

[40] May, M., Kayacelebi, A. A., Batkai, S., Jordan, J., Tsikas, D., Engeli, S. (2015): Plasma and tissue homoarginine concentrations in healthy and obese humans. - Amino acids 47(9): 1847-1852. doi: 10.1007/s00726-015-1922-4.

[41] Melikian, N., Seddon, M. D., Casadei, B., Chowienczyk, P. J., Shah, A. M. (2009): Neuronal nitric oxide synthase and human vascular regulation. - Trends in cardiovascular medicine 19(8): 256-262.

[42] Michel, T. (2013): $\mathrm{R}$ is for arginine: metabolism of arginine takes off again, in new directions. - Circulation:CIRCULATIONAHA. 113.005924.

[43] Moncada, S. (1991): Nitric oxide: physiology, pathophysiology, and pharmacology. Pharmacol rev 43: 109-142.

[44] Nathan, C. F., Hibbs Jr, J. B. (1991): Role of nitric oxide synthesis in macrophage antimicrobial activity. - Current opinion in immunology 3(1): 65-70.

[45] Olokoba, A. B., Obateru, O. A., Olokoba, L. B. (2012): Type 2 diabetes mellitus: a review of current trends. - Oman medical journal 27(4): 269.

[46] Papageorgiou, N., Androulakis, E., Papaioannou, S., Antoniades, C., Tousoulis, D. (2015): Homoarginine in the shadow of asymmetric dimethylarginine: from nitric oxide to cardiovascular disease. - Amino acids 47(9): 1741-1750. doi: 10.1007/s00726-015-2017-y.

[47] Pilz, S., Tomaschitz, A., Meinitzer, A., Drechsler, C., Ritz, E., Krane, V., Wanner, C., Böhm, B. O., März, W. (2011): Low serum homoarginine is a novel risk factor for fatal strokes in patients undergoing coronary angiography. - Stroke 42(4): 1132-1134.

[48] Pilz, S., Teerlink, T., Scheffer, P. G., Meinitzer, A., Rutters, F., Tomaschitz, A., Drechsler, C., Kienreich, K., Nijpels, G., Stehouwer, C. D. (2014): Homoarginine and mortality in an older population: the Hoorn study. - European journal of clinical investigation 44(2): 200208.

[49] Qiu, J., Zheng, Y., Hu, J., Liao, D., Gregersen, H., Deng, X., Fan, Y., Wang, G. (2014): Biomechanical regulation of vascular smooth muscle cell functions: from in vitro to in vivo understanding. - Journal of The Royal Society Interface 11(90): 20130852.

[50] Rao, S. L. (2011): A look at the brighter facets of beta-N-oxalyl-1-alpha,betadiaminopropionic acid, homoarginine and the grass pea. Food and chemical toxicology. British Industrial Biological Research Association 49(3): 620-622. doi: 10.1016/j.fct.2010.06.054. 
[51] Ryan, W. L., Wells, I. C. (1964): Homocitrulline and Homoarginine synthesis from lysine. - Science (New York, N.Y.) 144(3622): 1122-1127.

[52] Sakuma, I., Togashi, H., Yoshioka, M., Saito, H., Yanagida, M., Tamura, M., Kobayashi, T., Yasuda, H., Gross, S., Levi, R. (1992): NG-methyl-L-arginine, an inhibitor of Larginine-derived nitric oxide synthesis, stimulates renal sympathetic nerve activity in vivo. A role for nitric oxide in the central regulation of sympathetic tone? - Circulation Research 70(3): 607-611.

[53] Schwarz, P. M., Kleinert, H., Förstermann, U. (1999): Potential functional significance of brain-type and muscle-type nitric oxide synthase I expressed in adventitia and media of rat aorta. - Arteriosclerosis, thrombosis, and vascular biology 19(11): 2584-2590.

[54] Seppälä, I., Oksala, N., Jula, A., Kangas, A. J., Soininen, P., Hutri-Kähönen, N., März, W., Meinitzer, A., Juonala, M., Kähönen, M. (2017): The biomarker and causal roles of homoarginine in the development of cardiometabolic diseases: an observational and Mendelian randomization analysis. - Scientific reports 7(1): 1130.

[55] Shesely, E. G., Maeda, N., Kim, H.-S., Desai, K. M., Krege, J. H., Laubach, V. E., Sherman, P. A., Sessa, W. C., Smithies, O. (1996): Elevated blood pressures in mice lacking endothelial nitric oxide synthase. - Proceedings of the National Academy of Sciences 93(23): 13176-13181.

[56] Stockebrand, M., Hornig, S., Neu, A., Atzler, D., Cordts, K., Böger, R. H., Isbrandt, D., Schwedhelm, E., Choe, C.-u. (2015): Homoarginine supplementation improves blood glucose in diet-induced obese mice. - Amino acids 47(9): 1921-1929.

[57] Teerlink, T., Nijveldt, R. J., De Jong, S., Van Leeuwen, P. A. (2002): Determination of arginine, asymmetric dimethylarginine, and symmetric dimethylarginine in human plasma and other biological samples by high-performance liquid chromatography. - Analytical biochemistry 303(2): 131-137.

[58] Tomaschitz, A., Meinitzer, A., Pilz, S., Rus-Machan, J., Genser, B., Drechsler, C., Grammer, T., Krane, V., Ritz, E., Kleber, M. E. (2014): Homoarginine, kidney function and cardiovascular mortality risk. - Nephrology Dialysis Transplantation 29(3): 663-671.

[59] Tomkin, G. H., Owens, D. (2012): LDL as a cause of atherosclerosis. - The Open Atherosclerosis \& Thrombosis Journal 5(1): 13-21.

[60] Tousoulis, D., Kampoli, A.-M., Tentolouris Nikolaos Papageorgiou, C., Stefanadis, C. (2012): The role of nitric oxide on endothelial function. - Current vascular pharmacology 10(1): 4-18.

[61] Tsikas, D., Kayacelebi, A. A. (2014): Do homoarginine and asymmetric dimethylarginine act antagonistically in the cardiovascular system? - Circulation Journal 78(8): 2094-2095.

[62] Tsikas, D., Wu, G. (2015): Homoarginine, arginine, and relatives: analysis, metabolism, transport, physiology, and pathology. - Springer.

[63] Valtonen, P., Laitinen, T., Lyyra-Laitinen, T., Raitakari, O. T., Juonala, M., Viikari, J. S., Heiskanen, N., Vanninen, E., Punnonen, K., Heinonen, S. (2008): Serum L-homoarginine concentration is elevated during normal pregnancy and is related to flow-mediated vasodilatation. - Circulation Journal 72(11): 1879-1884.

[64] Vogl, L., Pohlhammer, J., Meinitzer, A., Rantner, B., Stadler, M., Peric, S. A., HammererLercher, A., Klein-Weigel, P., Fraedrich, G., Kronenberg, F., Kollerits, B. (2015): Serum concentrations of L-arginine and L-homoarginine in male patients with intermittent claudication: a cross-sectional and prospective investigation in the CAVASIC Study. Atherosclerosis 239(2): 607-614.

[65] Zhou, L., Zhu, D.-Y. (2009): Neuronal nitric oxide synthase: structure, subcellular localization, regulation, and clinical implications. - Nitric oxide 20(4): 223-230.

[66] Ziolo, M. T., Katoh, H., Bers, D. M. (2001): Positive and negative effects of nitric oxide on $\mathrm{Ca}(2+)$ sparks: influence of beta-adrenergic stimulation. - American journal of physiology, Heart and circulatory physiology 281(6): H2295-2303. doi: 10.1152/ajpheart.2001.281.6.H2295. 